\title{
On the Impact of Learning Cycle Teaching on Austrian High School Students' Emotions, Academic Self-Concept, Engagement, and Achievement
}

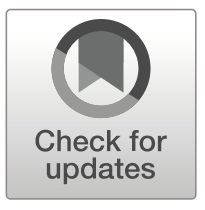

\author{
Franz Riffert ${ }^{1}$ (D) $\cdot$ Gerda Hagenauer $^{2} \cdot$ Josef Kriegseisen $^{3} \cdot$ Alexander Strahl $^{4}$
}

Published online: 25 January 2020

(C) The Author(s) 2020

\begin{abstract}
Over the past several decades, empirical support for inquiry-based forms of science teaching has accumulated. Critical voices, however, also exist, claiming that minimally guided teaching approaches might be less effective than guided forms; they might even be harmful, particularly for novice students, due to the production of cognitive overload. In this study, a more guided type of inquiry-based forms of instruction was therefore selected, which can be traced back to Alfred N. Whitehead: the so-called learning cycle approach. This approach was applied to science classes with 280 socioeconomically disadvantaged students in lower secondary education at low-track schools in Austria. Using a pre-test post-test experimental-control group design, this study investigated the effects of this instructional approach not only concerning students' cognitive development but also concerning their state and trait emotions, their behavioral engagement in class, and their academic self-concept. The results indicated that the application of the learning cycle approach had a positive impact on most of the measured students' trait emotions and state emotions during the romance and generalization phases of a full learning cycle. It further improved the students' behavioral engagement during lessons and strengthened their academic self-concept. Finally, it was found that the learning cycle approach positively affected the students' cognitive development after the 2-year treatment. Suggestions for improving the implementation of this teaching approach in science classes are given; some proposals for optimizing future research on learning cycle teaching are also made.
\end{abstract}

Keywords Learning cycle $\cdot$ Science education $\cdot$ Emotions $\cdot$ Self-concept $\cdot$ Behavioral engagement - Cognitive development

Franz Riffert

franz.riffert@sbg.ac.at

Extended author information available on the last page of the article 


\section{Introduction}

Efficiency studies in the domain of science teaching have traditionally focused solely on the cognitive achievement aspect of students' learning. Studies focusing on affective domains have frequently addressed only positive emotions (in particular, interest), thus neglecting negative emotions (besides anxiety) (Randler et al. 2015). Today, however, it is unquestioned that intervention studies must consider multiple dimensions and aims of high-quality teaching, including cognitive, social, emotional, and motivational aims.

Over the past several decades, empirical support has been accumulated for inquiry-based forms of science and technology teaching as potentially appropriate ways to teach science topics (e.g., Alfieri et al. 2011). Critical voices, however, also exist concerning inquiry-based instruction: Open, that is, minimally guided, teaching forms might be ineffective, while fully unguided instructional methods may even have negative effects on students, particularly for novices in a specific field, due to cognitive overload (Kirschner et al. 2006, p. 76). Möller (2016, p. 44) argues that socioeconomically "disadvantaged" students in particular might experience difficulties due to instruction based on low(er) guidance.

Following this argumentation, the present study aimed to test whether a specific inquiry-based teaching method that is more strongly guided, the so-called learning cycle approach (Karplus and Thier 1967; Whitehead 1929/1967), simultaneously supports students' achievement, academic emotions, academic self-concept, and engagement in science classrooms. The intervention study was conducted in lower secondary education in Austria, addressing students at low-track schools. This student group was intentionally chosen, as Austrian students in secondary education, particularly those attending low-track schools, exhibit lower interest in science, which ultimately endangers the successful acquisition of scientific literacy. The present study aimed to test whether so-called disadvantaged students can benefit from a more guided inquiry-based teaching method.

\section{Theoretical Background}

\section{Control-Value Theory}

To theoretically frame students' learning experiences in the science classroom, this study relied on control-value theory (CVT) (Pekrun 2006), which was developed to explain students' academic emotions in the classroom.

Based on an appraisal-theoretical approach to emotions (Ellsworth 2013), CVT states that emotions are triggered by a cognitive evaluation of the learning situation. In this appraisal process, control appraisals and value appraisals are of core importance. In the present study, students' appraisals were accounted for through the assessment of students' academic selfconcept as indicators of students' control appraisals. Typically, students experience more positive and less negative emotions if they exhibit high academic self-concept, which reflect high(er) perceived controllability of the learning situation (e.g., Goetz et al. 2010). Furthermore, CVT proposes that emotions trigger students' motivation and engagement in the classroom, thus positively affecting students' achievement (Pekrun 2006).

The logical expectation that accompanies reliance on this theoretically claimed chain of relations is that a positively perceived and experienced instructional approach positively affects students' cognition, emotions, behavior, and achievement, as these factors are all positively and reciprocally intertwined in CVT. 


\section{Emotions in Science Education}

Since the cognitive, motivational, and behavioral dimensions have been the focus of research on science teaching and learning for decades, there is hardly any need for justification. Although research has been conducted on students' interest in science (van Griethuijsen et al. 2015), academic emotions (enjoyment, boredom, pride, anger, etc.) in science education have been far less frequently explored thus far (Sinatra et al. 2014). Therefore, this dimension requires some special attention, particularly with regard to its definition.

Students' academic emotions are a type of emotion that is directly linked to academic learning, achievement activities, and achievement-related outcomes (Pekrun 2006). Furthermore, for a precise analysis of academic emotions, the difference between state and trait emotions must be considered. While trait emotions refer to habitualized emotional reactions to learning in science in general, state emotions are situation-specific emotional reactions (Frenzel et al. 2009).

Moreover, research has shown that students' academic emotions must be classified domainspecifically: Students report different emotions and different levels of emotional intensity in different school subjects (Goetz et al. 2006).

Generally, Sinatra et al. (2014) argue that little is known about the features of science instruction and their relation to students' academic emotions (see also Tomas and Ritchie 2012). It is clear, however, that many emotions accompany learning in science classes. These emotions are triggered by characteristics of the instruction and the content (e.g., Randler et al. 2015; Tomas and Ritchie 2012), and they are linked to students' learning (e.g., conceptual change), students' behavior and behavioral intentions, respectively (Fröhlich et al. 2013), and students' achievement (e.g., Hong et al. 2017; Liu et al. 2014). A number of experimental and quasi-experimental studies aiming to enhance students' emotions in science instruction have demonstrated that students' emotions can be fostered by the application of specific instructional strategies e.g., by integrating students' alternative conceptions in biology lessons (see Franke and Bogner 2013) or by using expressive writing in biology lessons (see Randler et al. 2015).

Gläser-Zikuda (2010), however, argues that, although the empirical basis for the relation between emotion and student learning has been steadily increasing, there is a pronounced absence of long-term intervention studies aiming to foster students' positive emotional experiences in school in general and in science instruction specifically. While it is possible to affect students' state emotions with relatively short-lasting interventions (e.g., Randler et al. 2015; Fröhlich et al. 2013; for a short scale to measure situational emotions, see Randler et al. 2011), it seems more difficult to induce changes in students' trait emotions. For instance, GläserZikuda et al. (2005) applied the so-called Emotional and Cognitive Aspects of Learning (ECOLE) approach in different school subjects and also in physics instruction, among other areas. The intervention had a relatively long duration of, namely, between 12 and 18 lessons and aimed at fostering students' cognitions and emotions. Against expectations, their results revealed no significant treatment effect for students' emotions (interest, anxiety, and boredom). Only a small positive effect for instruction-related well-being was found. The authors conclude that the intervention might has been too short to affect emotions sustainably, as trait emotions are relatively stable and, thus, difficult to influence. Therefore, they suggest that "more extensive interventions" (Gläser-Zikuda et al. 2005, p. 492) should be applied. This is where this study performs a useful function. 


\section{The Learning Cycle Approach}

Different teaching approaches in science teaching can foster cognitive development, positive emotional experiences, and engaged student behavior. The intervention in this study relied on the classical three-phase learning cycle (LC) instruction approach, which was introduced by the physicist Robert Karplus (1979) and was expected to achieve success in terms of supporting these aspects of student learning. The origin of this approach dates back to John Dewey (1916) and Alfred North Whitehead (1917) (see Lawson 2002). Based on a rhythmic understanding of learning processes, it follows the way in which people naturally learn (Lawson et al. 1989). In its classical form, the LC approach consists of a sequence of three phases: romance, precision, and generalization.

In the first phase, romance (exploration, according to Karplus), the aim is to induce the student to engage emotionally with a presented problem. It is a phase of free exploration that is not constrained in any respect. The student should connect with the given problem in whatever respects he or she wishes. Therefore, the focus in this phase resides on the pre-knowledge of the students and their free exploration of the presented problem.

In the second phase, precision (concept introduction, according to Karplus), the teacher changes his or her role: He or she is now active in introducing the basic scientific ideas necessary for solving the given problem. He or she presents the scientific concepts and theoretical underpinnings by connecting them to the experiences the students used to connect with the problem in phase one. The students play a more passive role in this phase: They listen, read prepared short input texts or web pages, watch video clips, or write down information.

Finally, in phase three, generalization (application, according to Karplus), the information input from phase two has to be applied to a new problem. The students are now once again free to undertake whatever activities they think will lead them to a solution. Therefore, this phase marks the "return to romance": A smooth transition to a new LC takes place (Whitehead 1929/1967, p. 20). Typical student and teacher activities are the same as in the romance phase; the only difference is that the students are now supposed to solve the problem using the newly acquired ideas that were presented in the precision phase.

The LC approach can be termed a moderate approach, rather than a radical constructivist approach, to learning and instruction. To secure the best effects, the sequence of phases should remain unchanged, and no phase should be bypassed (Abraham and Renner 1986; Renner et al. 1988). The teacher and student activities that characterize the different phases of the LC approach are summarized in Fig. 1. For further clarification, an example of a particular LC is described in the appendix ("Is water an element or a compound?").

The LC approach can be subsumed under the inquiry teaching procedures and is well aligned with the inquiry nature of science. It aims to promote inquiry-based learning, curiosity, and the enjoyment of inquiry. In LC-based environments, students actively construct their knowledge: They learn in a self-regulated, creative, and active manner based on their intellectual stage of development. The LC approach is in accordance with Piaget s mental functioning model (1952). New insights are expected to be included in the existing cognitive structures (assimilation); this can eventually lead to an adjustment of mental structures during the construction of the concepts (accommodation). The acquirement of new concepts through assimilation and accommodation is described as adaptation (Piaget 1952).

The LC approach is expected to be effective with regard to emotional and cognitive outcomes. Several studies, especially studies conducted in anglophone countries, have already tested the effectiveness of the LC approach. For example, studies have revealed that instruction 


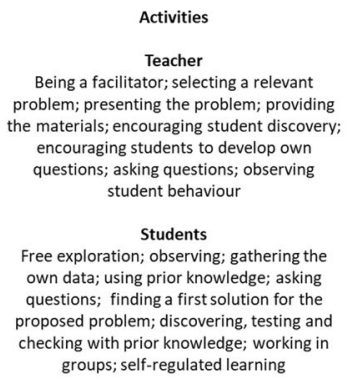
groups; self-regulated learning

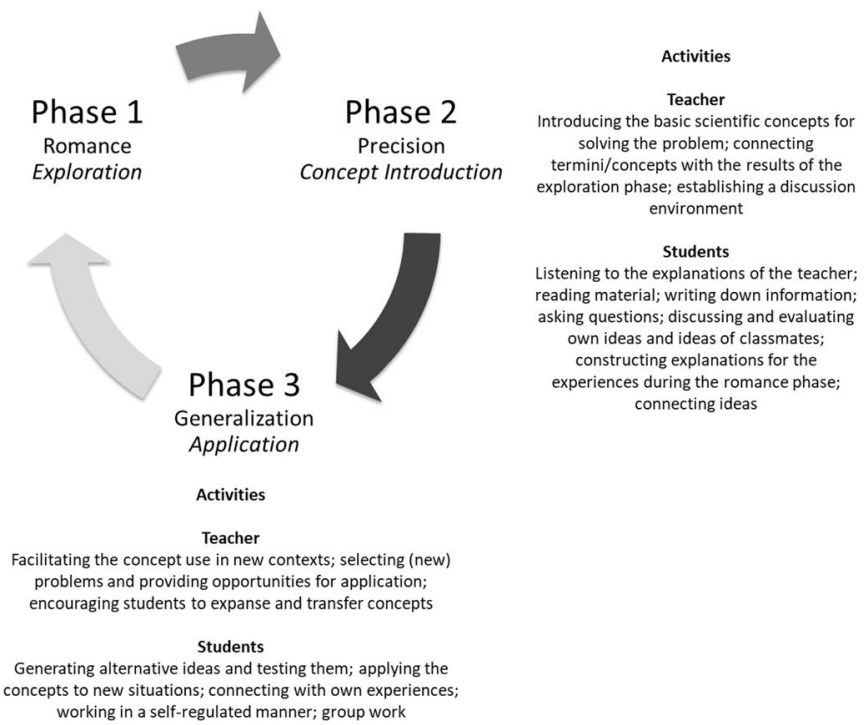

Fig. 1 Teacher and student activities in the three phases of a learning cycle

based on LC fosters higher cognitive skills, that is, it is effective with regard to developing students' understanding of scientific concepts (e.g., Musheno and Lawson 1999), addressing students' misconceptions and fostering conceptual change (e.g., Balci et al. 2006), and supporting students' reasoning skills (e.g., Marek and Methven 1991). Furthermore, studies have shown that teaching based on LC facilitates students' critical and creative thinking and positive attitudes toward science (Lawson 2002). Empirical evidence on the effectiveness of the LC approach with regard to students' specific distinct positive (e.g., pride) and negative (e.g., shame, anger) academic emotions, however, is missing, especially evidence based on long-term interventions for low-achieving students. In addition, empirical evidence on the effectiveness of the LC approach in German-speaking countries is rare (for a pilot study, see Riffert et al. 2009). Although inquiry-based approaches to teaching and learning are increasingly receiving emphasis in teacher education curricula in Austria, teachers do not typically receive specific training in the LC approach.

\section{Research Aims and Hypotheses}

The intervention study tested whether the LC approach achieved effective outcomes in terms of students' academic emotions (H1), academic self-concept (H2), behavior (H3), and cognitive development (H4) in science instruction in low-track Austrian science classrooms. Students who received the intervention were compared with students in a control group in terms of their academic emotions, academic self-concept, behavior, and cognitive development.

In addition, this study tested whether students' emotional experiences differed in connection with the specific phase in the LC. It was expected that students' positive emotions would be higher in the romance phase (H5a) and in the generalization phase (H5b) of a LC than the emotions of students in the control group. No difference in the emotional experiences was expected for the precision phase ( $\mathrm{H} 5 \mathrm{c})$.

This study adds to the literature in the field, as (1) multiple aims are considered simultaneously; (2) the long-neglected topic of emotion (positive and negative) is explicitly addressed; 
(3) the trait and state dimensions of academic emotions are measured; (4) a long-term intervention is applied; and (5) students from low-track schools participated in the study. The effectiveness of the LC will be tested by means of a program evaluation. Thus, the aim was not to evaluate how single activities in the LC worked out (e.g., experimentation in the romance phase) but to evaluate the overall effects of the program (i.e., the LC approach) as a specific form of cyclic teaching in science instruction.

\section{Design}

A quasi-experimental treatment control group design with pre-experiment and post-experiment measurements was chosen. The pre-experiment measurement took place at the beginning of the school year, before the treatment started. The post-experiment measurement took place after 1 school year for all intervention groups and after 2 school years for the 2-year intervention groups. In addition, to check whether the teachers implemented the LC appropriately and to explore students' state emotions, two randomly selected LCs were evaluated during the school year (see Fig. 2).

The students in the treatment group received LC instruction for 1 or 2 consecutive school years, reflecting a constructivist inquiry-based teaching approach (see the section entitled "The Learning Cycle Approach"), while the students in the control group were taught according to socalled expository teaching. In an expository teaching and learning environment, students are not as actively involved in scientific activities (e.g., in collecting data and experimenting) but are rather predominantly informed about the learning content, and the environment is more strongly teacher-centered. Moreover, the students are less active, and the instruction is not rhythmically based on different phases that interdigitate. If experiments are conducted (mainly by the teacher), they are administrated after the basic concepts have been introduced as a validation of these concepts (inform/verify/practice as the basic processes of expository teaching; see Renner 1982).

\section{Participants}

A total of 280 Austrian high school students and their science teachers $(N=7)$ at a "Neue Mittelschule" participated in the study. Participation was voluntary. Austria has a tracked school system. After elementary school (grades 1-4), students can attend either a "Gymnasium," which is the high-track school type, or a "Neue Mittelschule," which is the low-track school type.

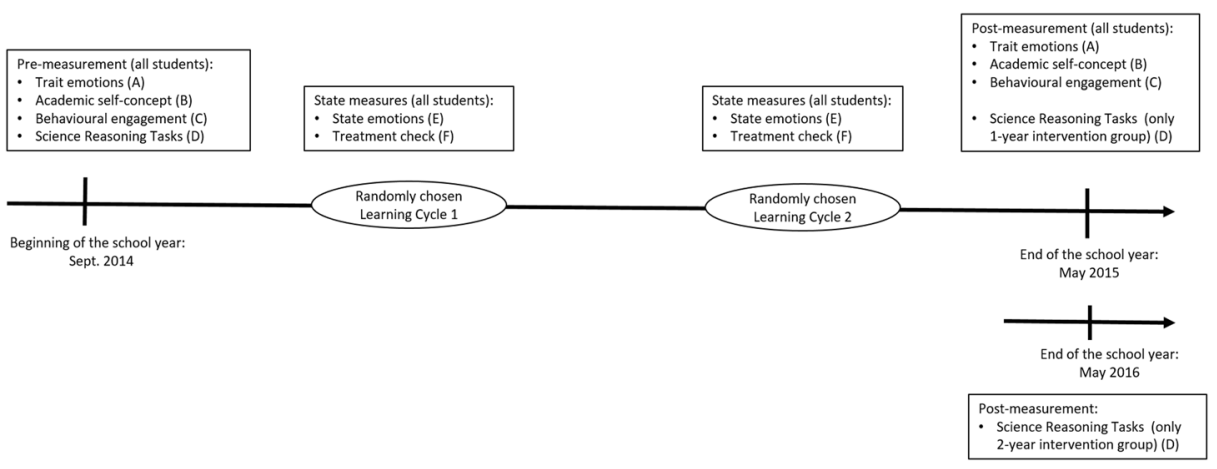

Fig. 2 Research design 
The students in the present study were in grades 6 to 8 (18.8\% were sixth graders, $64.5 \%$ were seventh graders, and $16.7 \%$ were eighth graders). Of the participants, 142 (40.9\% boys, $59.1 \%$ girls) were in the treatment group and received the learning-cycle-based instruction, and 138 (50.7\% boys, $49.3 \%$ girls) were in the control group.

The mean age of the students was $M=12.60$ years $(S D=0.96$, range $=11-14)$. Of the students, $63.9 \%$ spoke German as their mother language, and $88.1 \%$ were born in Austria.

The participating teachers had several years of teaching experience. Since it is well documented that the teacher plays a decisive role in the achievement of the students, this central variable was controlled for by having each participating teacher teach both a treatment and a control class of the same year level.

\section{Teacher Training}

The participating teachers received training, one full day and three half-days of training, in teaching according to the LC approach; this training included an introduction to the philosophy of science (Bunge 2017) and an introduction to Piaget's genetic structuralism, focusing on his concepts of equilibration-disequilibration and re-equilibration (Piaget 1985).

To become familiar with the instruction concept of LC, teaching, and the role the teacher plays in the different phases (including the central role of stating questions) (Lawson 2002, pp. 182-184), the teachers progressed through three LC dealing with electricity. Staver and Shroyer (1994) elaborated these three learning cycles. Progressing through these LC gave the teachers an opportunity to experience the phases of LC instruction. In addition, some selected LC presented in Lawson (2002, Appendix G, pp. 447-571) were used as LC models. Finally, the teacher training followed "A Teacher's Guide to the Learning Cycle" by Campbell and Fuller (1982, Chapter 4).

The teachers teaching the same year level formed work groups in which they collaboratively developed LC according to the content demands of their respective curricula. The teachers had to teach the same content (albeit using different instruction methods) in both classes (treatment and control). ${ }^{1}$

\section{Instruments}

\section{Academic Trait Emotions (Pre-Post Measurement)}

Students' trait emotions were measured by means of a short version of the Achievement Emotions Questionnaire (AEQ) (Pekrun et al. 2005), a valid and reliable measure of academic emotions (see Fig. 2: A). Overall, seven emotions were differentiated:

- Joy (six items; Cronbach's $\alpha_{\mathrm{t} 1 / 2}=.87 / 87$ ), for example, "I get excited about going to class";

- Pride (four items; Cronbach's $\alpha_{\mathrm{t} 1 / \mathrm{t} 2}=.72 / .79$ ), for example, "I take pride in being able to keep up with the material";

- Anger (four items; Cronbach's $\alpha_{\mathrm{t} 1 / \mathrm{t} 2}=.76 / .74$ ), for example, "I feel frustrated in class";

- Anxiety (three items; Cronbach's $\alpha_{\mathrm{t} 1 / \mathrm{t} 2}=.68 / .69$ ), for example, "Thinking about class makes me feel uneasy";

\footnotetext{
${ }^{1}$ More details on the teacher training in the present study can be directly obtained from the authors.
} 
- Shame (four items; Cronbach's $\alpha_{\mathrm{t} 1 / \mathrm{t} 2}=.77 / .80$ ), for example, "When I say something in class, I feel I am making a fool of myself";

- Hopelessness (four items; Cronbach's $\alpha_{\mathrm{t} 1 / \mathrm{t} 2}=.74 / .78$ ), for example, "The thought of this class makes me feel hopeless";

- Boredom (four items; Cronbach's $\alpha_{\mathrm{t} 1 / \mathrm{t} 2}=.75 / .80$ ), for example, "I get bored in class."

The items were answered on a Likert scale ranging from "not true at all" (1) to "true" (5).

\section{Academic State Emotions (Short Questionnaire)}

State emotions were measured after each LC phase of two randomly selected LC during the first intervention year, resulting in six measurement points (see Fig. 2: E). The students rated the intensity ( 1 = little intensity; $5=$ high intensity) of their state emotions on a dartboard-like figure consisting of joy, interest, pride, and boredom (reverse-coded). The internal consistency of this positive emotion scale was high across all six measurement points (Cronbach's $\alpha$ $\mathrm{LC} 1=.80 / .81 / .85 ;$ Cronbach's $\alpha \mathrm{LC} 2=.82 / .85 / .87)$.

\section{Academic Self-Concept}

Academic self-concept was measured with six items on a scale ranging from $1=$ "do not agree at all" to $4=$ "fully agree" (e.g., "It is easy for me to understand new ideas in science instruction”) (Cronbach's $\alpha_{\mathrm{t} 1 / 22}=.88 / .91$ ) (Frey et al. 2009; PISA 2006) (see Fig. 2: B).

\section{Behavioral Engagement}

Behavioral engagement was assessed with a scale developed by Skinner et al. (2008). This scale was translated into German (see Fig. 2: C). An example item (out of five items) is "In class, I work as hard as I can" (Cronbach's $\alpha_{\mathrm{t} 1}=.77$; Cronbach's $\alpha_{\mathrm{t} 2}=.82$; from $1=$ "do not agree at all" to $4=$ "fully agree").

\section{Cognitive Dimension}

To grasp the effect of the intervention on the students' cognitions, the so-called Science Reasoning Tasks (SRT) were used (see Fig. 2: D). ${ }^{2}$ This instrument is a group test developed for application in school settings (Adey et al. 2001; Shayer et al. 1981). It is based on Piaget's so-called clinical interviews. These tasks "are a well-documented, validated measure to gauge the cognitive level of students" (Venville and Oliver 2015, p. 53). The instrument was Raschscaled so that a fairly sensitive attribution of one of seven Piagetian cognitive sub-stages (ranging from early concrete to mid concrete, mature concrete, concrete generalization, early formal, mature formal, and formal generalization) to each student would be possible (Shayer and Adhami 2007). From the seven tasks, two were selected: task 4, "Equilibrium and Balance," was used in the pre-test, while task 2, "Volume and Heaviness," was implemented in the post-test in both treatment and control groups. These two tasks were selected because

\footnotetext{
${ }^{2}$ The authors thank Michael Shayer from King's College, London, for the permission to use the Science Reasoning Tasks.
} 
they had been successfully used in studies on the efficiency of the Cognitive Acceleration through Science Education program (Oliver and Venville 2016).

Intercoder reliability (Cohen's kappa; see Lombard 2010) based on two independent raters (who were both physicists and physics trainers) was calculated and revealed highly satisfactory interrater agreement: kappa was .98 for both tasks ("Volume and Heaviness" and "Equilibrium and Balance") ( $n=736$ double codings for "Volume and Heaviness" and $n=700$ double codings for "Equilibrium and Balance").

\section{Treatment Validity}

To secure correct treatment implementation, two measures were taken (see Fig. 2: F). First, training in LC instruction was designed and given to the participating teachers to ensure that they would be able to implement the treatment correctly. Second, in two selected learning cycles, a treatment check was conducted to check if/to what extent the treatment was in fact realized. Altogether, six items were presented to the students of all groups after each of the three phases in the treatment classes; these items were simultaneously presented to students in the control classes. Three of the items described typical student and teacher activities in the romance and the generalization phases, and three of the items represented activities in the precision phase and typical activities of students and teachers in the traditional, more teachercentered teaching design.

Overall, the treatment was successfully implemented: Levels of group work and independent work, for example, were significantly higher in the romance and generalization phases, while levels of teacher-centered instruction were higher in the precision phase (see Table 1).

\section{Results}

\section{Descriptive Statistics and Intercorrelations}

The intercorrelations reveal positive associations between students' positive academic emotions, academic self-concept, and behavioral engagement, while these relations were negative with students' negative academic emotions (see Table 2).

\section{Changes in Students' Emotions, Academic Self-Concept, and Behavioral Engagement After 1 School Year}

As there were significant differences in some of the dependent variables between the treatment and control groups at $\mathrm{t}_{1}$ (students in the treatment groups expressed higher enjoyment, less anger, and less boredom, $p<.05$ ), a MANCOVA controlling for the pre-test variables as well as grade point average (GPA) for the main subjects mathematics, German, and second language was conducted to test for intervention effects.

The results demonstrated that positive emotions, academic self-concept, and behavioral engagement decreased from $t_{1}$ to $t_{2}$, while negative emotions increased. This effect can be observed in both groups, with one exception: Students' reported shame in the intervention group decreaseds from $t_{1}$ to $t_{2}$, while it increaseds in the control group. It has to be noted that $t_{1}$ was realized at the beginning of the school year and $t_{2}$ at the end of the school year; thus, 
Table 1 Treatment check, learning cycle 1, and learning cycle 2 for all three phases for the treatment groups (TG) and control groups (CG)

\begin{tabular}{|c|c|c|c|c|c|c|}
\hline & \multicolumn{2}{|l|}{ Romance } & \multicolumn{2}{|l|}{ Precision } & \multicolumn{2}{|c|}{ Generalization } \\
\hline & $Z$ & $M \mathrm{TG} / \mathrm{CG}$ & $Z$ & $M \mathrm{TG} / \mathrm{CG}$ & $Z$ & $M \mathrm{TG} / \mathrm{CG}$ \\
\hline \multicolumn{7}{|l|}{ Learning cycle 1} \\
\hline We worked in small groups. & $-7.01 * * *$ & $3.61>2.29$ & -.25 & $2.35>2.27$ & $-2.96^{* *}$ & $2.62>2.00$ \\
\hline $\begin{array}{l}\text { The teacher offered us ideas } \\
\text { and suggestions for } \\
\text { working independently. }\end{array}$ & $-3.49 * * *$ & $3.57>2.88$ & -1.22 & $3.02>2.83$ & $-4.27 * * *$ & $3.17>2.54$ \\
\hline $\begin{array}{l}\text { The teacher let us work } \\
\text { on our own. }\end{array}$ & $-5.24 * * *$ & $4.06>3.21$ & -.76 & $3.09>2.96$ & $-4.65 * * *$ & $3.36>2.60$ \\
\hline We wrote down information. & $-3.70 * * *$ & $2.43<2.99$ & $-2.56^{* *}$ & $4.17>2.96$ & $-2.85^{* *}$ & $3.02>2.53$ \\
\hline The teacher lectured. & -.81 & $3.50<3.54$ & -.05 & $3.50>3.44$ & -.14 & $3.28>3.20$ \\
\hline $\begin{array}{l}\text { The teacher explained } \\
\text { physical/chemical terms } \\
\text { to students. }\end{array}$ & -1.54 & $3.52>3.27$ & -.11 & $3.23>3.22$ & .68 & $3.01>2.98$ \\
\hline \multicolumn{7}{|l|}{ Learning cycle 2} \\
\hline We worked in small groups. & -.35 & $2.68<2.75$ & $-7.55 * * *$ & $3.47>1.75$ & -.24 & $2.42<2.52$ \\
\hline $\begin{array}{l}\text { The teacher offered us } \\
\text { ideas and suggestions for } \\
\text { working independently. }\end{array}$ & $-1.99 *$ & $3.49>2.87$ & $-3.33^{* *}$ & $3.49>2.87$ & $-2.22^{*}$ & $3.17>2.71$ \\
\hline $\begin{array}{l}\text { The teacher let us work } \\
\text { on our own. }\end{array}$ & -1.25 & $3.83>3.59$ & $-2.23 *$ & $3.69>3.32$ & -.45 & $3.58>3.40$ \\
\hline We wrote down information. & -.67 & $3.09<3.27$ & -1.26 & $3.42>3.20$ & $-4.85 * * *$ & $3.26>2.29$ \\
\hline The teacher lectured. & -.68 & $3.39<3.52$ & -1.77 & $3.60<3.87$ & $-3.48 * *$ & $3.62>2.89$ \\
\hline $\begin{array}{l}\text { The teacher explained } \\
\text { physical/chemical terms } \\
\text { to students. }\end{array}$ & -.39 & $3.13<3.07$ & -1.41 & $3.25>3.01$ & $-2.56^{* *}$ & $3.20>2.70$ \\
\hline
\end{tabular}

Items in italics are those which describe desirable/typical teacher and student activities for the romance and generalization phases; items not in italics describe typical activities during the precision phase. Two control classes did not fill in the short questionnaires. Thus, the evaluation of the second learning cycle was based on $N=$ 191 ( $N=99$ treatment group; $N=92$ control group) students, excluding the treatment group and the control group of these two schools (to keep possible teacher effects constant)

$* * * p<.001 ; * * p<.01 ; * p<.05 ; Z$ values resulting from Mann-Whitney $U$ tests

possible effects of the school year have to be taken into account (e.g., increased tiredness at the end of the school year).

To test for intervention effects, the effect of group affiliation on the change in the dependent variables was of interest. The results revealed a significant group effect (Pillai's trace $=.094$, $F(9,260)=2.99, p<.001$, partial $\left.\eta^{2}=.094\right)$. Concretely, there was more positive development in students' joy, pride, academic self-concept, and behavioral engagement in the LC group than in the control group. Furthermore, the change in students' experiences of shame, boredom, and anger was more positive in the intervention group. No intervention effects could be detected for anxiety and hopelessness (see Table 3).

\section{Changes in Students' Scientific Reasoning Skills After 1 and 2 School Year(s)}

An ANCOVA was calculated to test for the change in students' scientific reasoning skills from pre-measurement to post-measurement. Some students participated in the post-SRT after 1 year of treatment $\left(N_{\mathrm{TG}}=49 ; N_{\mathrm{CG}}=45\right)$, and the other subsample participated in the post-SRT after 2 years of treatment $\left(N_{\mathrm{TG}}=93 ; N_{\mathrm{CG}}=93\right)$. As the students in the two groups differed in 
Table 2 Means, standard deviations, and intercorrelations

Joy Pride Anger Anxiety Shame Hopelessness Boredom Self-concept Behavioral

engagement

\begin{tabular}{lcrrrrrrrr}
\hline Joy & - & .82 & -.62 & -.39 & -.19 & -.48 & -.63 & .59 & .66 \\
Pride & .75 & - & -.57 & -.38 & -.20 & -.50 & -.52 & .61 & .63 \\
Anger & -.48 & -.44 & - & .64 & .36 & .68 & .70 & -.57 & -.52 \\
Anxiety & -.17 & -.23 & .53 & - & .44 & .66 & .53 & -.51 & -.33 \\
Shame & -.16 & -.22 & .35 & .37 & - & .58 & .29 & -.43 & -.17 \\
Hopeless. & -.47 & -.48 & .66 & .55 & .52 & - & .60 & -.60 & -.36 \\
Boredom & -.52 & -.54 & .72 & .46 & .32 & .71 & - & -.45 & -.66 \\
Self-c. & .40 & .43 & -.29 & -.15 & -.34 & -.35 & -.26 & - & .54 \\
Engagem. & .47 & .47 & -.37 & -.13 & -.04 & -.26 & -.41 & .22 & - \\
$M \mathrm{t}_{1}$ & 3.63 & 3.81 & 1.86 & 1.63 & 2.07 & 1.67 & 1.82 & 2.90 & 3.33 \\
$S D \mathrm{t}_{1}$ & 0.95 & 0.89 & 0.88 & 0.80 & 0.99 & 0.85 & 0.88 & 0.81 & 0.70 \\
$M \mathrm{t}_{2}$ & 3.30 & 3.49 & 1.91 & 1.72 & 1.99 & 1.76 & 1.98 & 2.75 & 3.12 \\
$S D \mathrm{t}_{2}$ & 0.93 & 0.92 & 0.84 & 0.82 & 0.95 & 0.85 & 0.92 & 0.71 & 0.69 \\
\hline
\end{tabular}

All correlations were significant, except the correlation between shame and behavioral engagement at $t_{1}$. The correlations on the left-hand side below the diagonal are from $\mathrm{t}_{1}$; the correlations on the right-hand side above the diagonal are from $t_{2}$

relevant characteristics in the pre-measurement, enjoyment, anger, boredom, and academic self-concept were controlled for (as well as the pre-score of SRT).

The results indicated that there was an increase in students' scientific reasoning skills after 1 year of treatment in both groups; however, this increase was not significantly higher in the treatment group, although the effect size points to the expected direction, reflecting more

Table 3 Intervention effects: results of the MANCOVA and effect sizes of change within groups (Cohen's $d$ )

\begin{tabular}{|c|c|c|c|c|c|c|c|c|}
\hline & \multirow[b]{2}{*}{$\begin{array}{l}F \\
(1,268)\end{array}$} & \multirow[b]{2}{*}{ Partial $\eta^{2}$} & \multicolumn{3}{|c|}{ Treatm. group $(N=142)$} & \multicolumn{3}{|c|}{ Control group $(N=138)$} \\
\hline & & & $\begin{array}{l}\mathrm{t}_{1} \\
M \\
(S D)\end{array}$ & $\begin{array}{l}\mathrm{t}_{2} \\
M \\
(S D)\end{array}$ & Cohen's $d$ & $\begin{array}{l}\mathrm{t}_{1} \\
M \\
(S D)\end{array}$ & $\begin{array}{l}\mathrm{t}_{2} \\
M \\
(S D)\end{array}$ & Cohen's $d$ \\
\hline Joy & $16.71 * * *$ & .059 & $\begin{array}{c}3.75 \\
(0.87)\end{array}$ & $\begin{array}{c}3.55 \\
(0.87)\end{array}$ & $.26^{*}$ & $\begin{array}{c}3.51 \\
(1.01)\end{array}$ & $\begin{array}{c}3.04 \\
(0.93)\end{array}$ & $.42 * * *$ \\
\hline Pride & $6.80 * *$ & .025 & $\begin{array}{c}3.90 \\
(0.83)\end{array}$ & $\begin{array}{l}3.65 \\
(0.87)\end{array}$ & $.29 * *$ & $\begin{array}{c}3.72 \\
(0.94)\end{array}$ & $\begin{array}{l}3.31 \\
(0.93)\end{array}$ & $.35 * * *$ \\
\hline Anger & $4.22 *$ & .015 & $\begin{array}{c}1.73 \\
(0.68)\end{array}$ & $\begin{array}{c}1.77 \\
(0.78)\end{array}$ & -.05 & $\begin{array}{c}1.99 \\
(1.04)\end{array}$ & $\begin{array}{c}2.04 \\
(0.89)\end{array}$ & -.04 \\
\hline Anxiety & 1.89 & .007 & $\begin{array}{c}1.56 \\
(0.68)\end{array}$ & $\begin{array}{c}1.65 \\
(0.81)\end{array}$ & -.08 & $\begin{array}{c}1.69 \\
(0.90)\end{array}$ & $\begin{array}{c}1.80 \\
(0.82)\end{array}$ & -.09 \\
\hline Shame & $5.32 *$ & .019 & $\begin{array}{c}2.10 \\
(0.94)\end{array}$ & $\begin{array}{l}1.88 \\
(0.83)\end{array}$ & $.29 * *$ & $\begin{array}{c}2.03 \\
(1.04)\end{array}$ & $\begin{array}{c}2.11 \\
(1.06)\end{array}$ & -.08 \\
\hline Hopelessness & 2.68 & .010 & $\begin{array}{c}1.58 \\
(0.73)\end{array}$ & $\begin{array}{l}1.65 \\
(0.79)\end{array}$ & -.08 & $\begin{array}{c}1.77 \\
(0.95)\end{array}$ & $\begin{array}{l}1.88 \\
(0.90)\end{array}$ & -.12 \\
\hline Boredom & $7.15^{* *}$ & .026 & $\begin{array}{c}1.72 \\
(0.80)\end{array}$ & $\begin{array}{c}1.80 \\
(0.82)\end{array}$ & -.10 & $\begin{array}{c}1.93 \\
(0.94)\end{array}$ & $\begin{array}{c}2.16 \\
(0.98)\end{array}$ & $-.21 *$ \\
\hline $\begin{array}{l}\text { Academic } \\
\text { self-concept }\end{array}$ & $15.80 * * *$ & .056 & $\begin{array}{c}2.98 \\
(0.87)\end{array}$ & $\begin{array}{c}2.88 \\
(0.70)\end{array}$ & .11 & $\begin{array}{c}2.81 \\
(0.73)\end{array}$ & $\begin{array}{c}2.61 \\
(0.70)\end{array}$ & $-.24 * *$ \\
\hline $\begin{array}{l}\text { Behavioral } \\
\text { engagement }\end{array}$ & $6.45^{*}$ & .023 & $\begin{array}{c}3.38 \\
(0.74)\end{array}$ & $\begin{array}{c}3.28 \\
(0.60)\end{array}$ & $.17 *$ & $\begin{array}{c}3.26 \\
(0.64)\end{array}$ & $\begin{array}{c}2.95 \\
(0.73)\end{array}$ & $.44 * * *$ \\
\hline
\end{tabular}

$* * * p<.001 ; * * p<.01 ; * p<.05 ; d>.02=$ small effect; $d>.05=$ moderate effect; $d>.08=$ large effect (Cohen 1988) 
pronounced development in the treatment group (group effect: $F(1,87)=1.36, p=.246$, partial $\eta^{2}=.015$ ). The gain in scientific reasoning skills was clearly higher and approaching significance for students in both groups after 2 years of treatment, and, in line with our hypothesis, the treatment group outperformed the control group (group effect: $F(1,179)=5.18, p=.024$, partial $\eta^{2}=.028$ ) (see Table 4 and Fig. 3).

\section{Students' Positive State Emotions During the Phases of a Learning Cycle}

A MANCOVA was conducted to test for differences in the positive state emotional patterns referring to the previous science class, controlling for students' trait characteristics.

Learning cycle 1: The results indicated that there was a significant effect of the instructional approach (treatment) on students' positive emotional experiences in science when controlling for students' trait characteristics at $\mathrm{t}_{1}$ (trait emotions and trait academic self-concept) $(N=280$, Pillai's trace $=0.056, F(3,271)=5.69, p=.001$; partial $\left.\eta^{2}=.059\right)$. The results revealed a significantly more intensive positive emotional pattern in the romance phase $(F(1,273)=$ $13.25, p<.001$, partial $\left.\eta^{2}=.046\right)$ and in the generalization phase $(F(1,273)=10.55, p=.001$, partial $\left.\eta^{2}=.037\right)$; meanwhile, no significant differences were found in the precision phase $\left(F(1,273)=1.66, p=.199\right.$, partial $\left.\eta^{2}=.001\right)$ (see Fig. 4).

Learning cycle 2: Two control classes did not fill in the short questionnaires. Thus, the evaluation of the second LC was based on $N=191$ ( $N=99$ treatment group; $N=92$ control group) students, excluding the treatment and the control group of these two schools (to keep possible teacher effects constant). Again, the results demonstrated that the treatment group experienced a more intensive positive emotional pattern than the control group, but the difference was weaker in comparison to that observed in the first LC ( $N=191$, Pillai's trace $=0.041, F(3,182)=2.62, p=.052$, partial $\left.\eta^{2}=.041\right)$. In contrast to the first LC, a significant difference could be observed in all three phases of the LC (romance: $F(1,184)=$ 5.17, $p=.024$, partial $\eta^{2}=.027$; precision: $F(1,184)=6.53, p=.011$, partial $\eta^{2}=.034$; generalization: $F(1,184)=5.10, p=.025$, partial $\left.\eta^{2}=.027\right)($ see Fig. 5).

\section{Discussion}

The present study aimed to investigate the effects of the LC approach on students' trait and state academic emotions, academic self-concept, behavioral engagement, and cognitive development.

Table 4 Within-group effects regarding the change in students' scientific reasoning skills from $t_{1}$ to $t_{2}$

\begin{tabular}{lllll}
\hline & & $\mathrm{t}_{1}$ & $\mathrm{t}_{2}$ \\
& & $M(S D)$ & $M(S D)$ & Cohen's $d$ \\
\hline 1-year intervention & Treatm. group $(n=49)$ & $5.68(.75)$ & $6.27(.89)$ & .60 \\
& Control group $(n=45)$ & $5.71(.75)$ & $6.03(.85)$ & .36 \\
2-year intervention & Treatm. group $(n=93)$ & $5.26(.51)$ & $6.93(1.19)$ & 1.53 \\
& Control group $(n=93)$ & $5.35(.55)$ & $6.63(.88)$ & 1.37 \\
\hline
\end{tabular}

All mean differences from $t_{1}$ to $t_{2}$ were significant. The effect sizes were calculated based on $t$ tests for dependent samples (formula: mean difference / standard deviation of the difference). Normally, level codes are reported as whole numbers (e.g., 5, 6, 7). As the results were based on a missing-imputed dataset, decimal places arose 


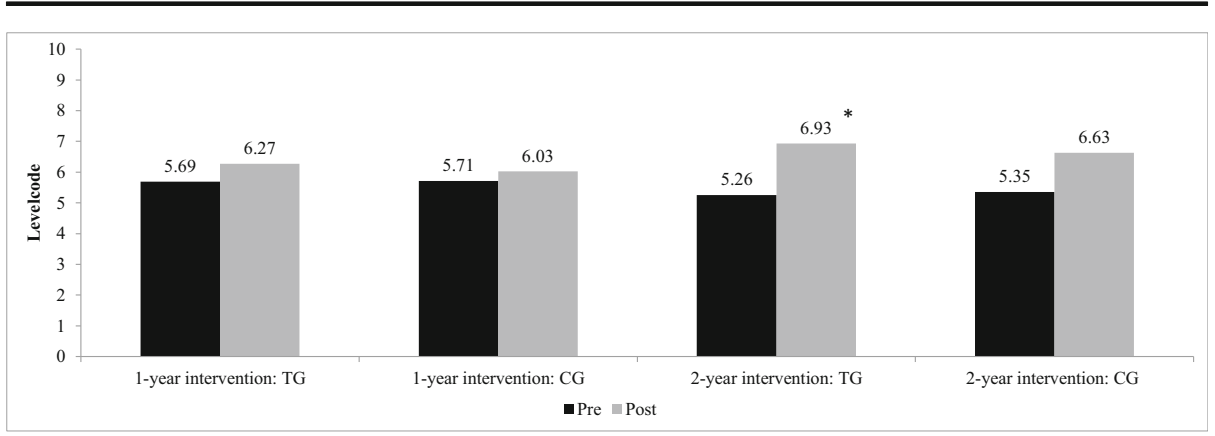

Fig. 3 The change in students' scientific reasoning skills from pre- to post-measurement

Starting with the long-neglected topic of emotions in science education (Sinatra et al. 2014), the data revealed that, in line with our expectations, the trait emotional pattern of students developed more positively in the LC group than in the control group. These positive effects, however, were not able to counterbalance an overall negative emotional trend as reflected by a decrease in students' positive trait emotions and an increase in students' negative trait emotions during the intervention periods. Nevertheless, this general trend was significantly weaker for students in the LC group. This indicates that the LC approach can significantly reduce negative trends in the domain of emotions. The intervention effect was particularly high for students' enjoyment in science, and it was also substantial for students' pride, anger, shame, and boredom. Therefore, Hypothesis 1 was supported, except for when considering students' levels of anxiety and hopelessness, which did not differ between the two conditions.

The missing effect on students' anxiety and hopelessness might be explained by the fact that the LC instruction did not specifically target test situations in science classes. According to Pekrun et al. (2014), anxiety and hopelessness can be regarded as outcome emotions related to experiences of failure and are thus strongly bound to performance situations at school. Therefore, future interventions under the LC approach might explicitly consider how to design performance situations appropriately to positively support a reduction in anxiety and hopelessness.

Concerning students' academic self-concept and behavioral engagement, the data revealed an increase in both factors, which results in the acceptance of Hypotheses 2 and 3.

As far as the effects on the cognitive dimension are concerned, the results indicated that the 2-year intervention groups benefited significantly more than the 1-year groups from the LC

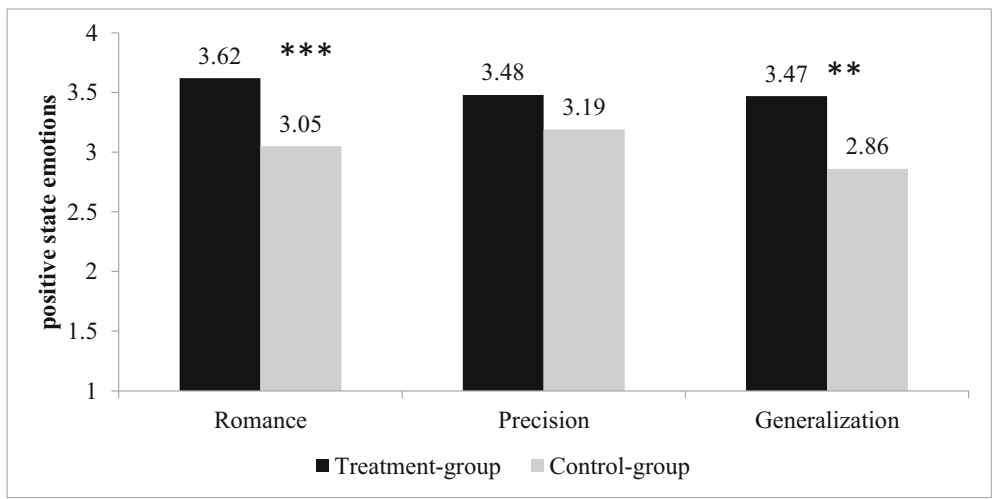

Fig. 4 Students' state emotions during the three phases of learning cycle 1 


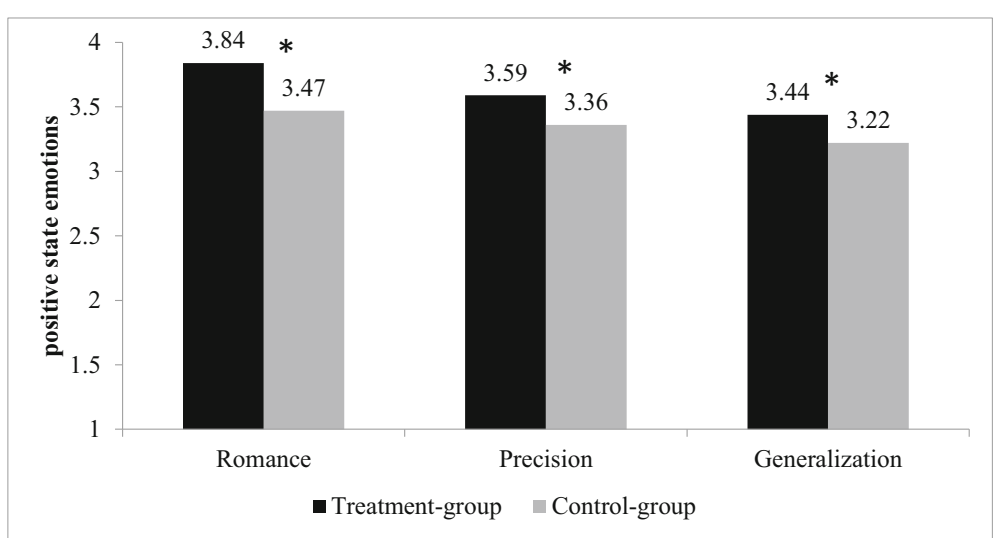

Fig. 5 Students' state emotions during the three phases of learning cycle 2

instruction. This is in accordance with Michael Shayer's warning (personal communication) not to expect any measurable effect from the demanding LC intervention that is applied no longer than a single year. If this temporal constraint is taken into account, it is possible to assert that Hypothesis 4 is supported. Since no empirical evidence showing that the LC approach leads to cognitive gains in low-achieving students has been available thus far, this result is particularly interesting.

Concerning students' state emotions, the expected results were obtained; Hypothesis 5 is thus supported. It was observed that differences in the teaching behavior were directly reflected in students' academic emotions. This finding is in line with previous studies, which have shown the effects of different forms of instruction on students' state emotions (e.g., Franke and Bogner 2013). The open forms of instruction (romance and generalization) triggered stronger positive emotional responses in students, while strongly teacher-led forms of instruction decreased students' positive emotional experiences. Learning, however, is not only associated with positive emotional experiences: it also evokes negative emotions. Recently, researchers' interest in students' epistemic emotions (e.g., curiosity, frustration, surprise; Muis et al. 2018) has been steadily increasing. It will be of core interest in future research not only to address students' academic emotions but also to explore epistemic emotions in order to penetrate more completely the emotional experiences of students' learning in science education.

Although our study provided evidence of the beneficial effects of the LC approach on students' emotions, academic self-concept, behavioral engagement, and cognitive development, several limitations should be acknowledged. First, the teachers and their students were not randomly assigned to either the intervention or control condition. Furthermore, the sample size was not very large. This might have caused problems in terms of statistical power. An attempt was made to account for this by reporting effect sizes in the analyses. In addition, the teachers developed the LCs themselves; thus, the intervention was not standardized in terms of the use of specific instructional material but "only" in terms of the basic principles regarding the use of the LC approach. Closely related to this issue, the treatment check used in this study only covered the formal activities of teachers and students during the lessons; content aspects, such as the quality of questions and motivating feedback, were not measured. The quality of the problems used in the romance and generalization phases was not measured, either. In future studies, an observation tool developed for the LC instruction approach (Riffert 2008) would be helpful for an in-depth investigation of the quality of the treatment implementation. 
It is also important to draw attention to the fact that the LC approach was implemented during 50-minute units and 100-minute units during the school year. This raises the question of whether all students had sufficient time for free inquiry during the romance and generalization phases. To reduce this problem, the LC instruction approach could be implemented in science projects lasting for 2-3 days without any artificial interruptions.

Finally, since it has been demonstrated that self-efficacy has positive effects on students' academic motivation, learning, and achievement (Schunk and DiBenedetto 2016) and that inquiry-based instruction can improve students' self-efficacy (Jansen et al. 2015), one can lament this study's failure to measure students' self-efficacy. In future research, this variable should also be included. Here, however, measurements would need to be planned carefully, since simply asking the students in the treatment and control groups the same questions about their selfefficacy convictions concerning their physics/chemistry classes would measure different constructs. Thus, measurement of self-efficacy should be closely tied to the form of instruction.

\section{Outlook, Conclusion, and Implications}

Beyond the suggestions outlined above for improving future research, there are some generally interesting directions for future research.

First, it would be interesting to apply the test battery to students attending high-track schools in Austria ("Gymnasium"). Since these schools usually offer students different foci on specific subjects - such as the arts, languages, and the sciences - it would also be fascinating to test the impact of LC teaching on students who have chosen a science focus.

Second, it is possible to speculate as to whether the LC approach could be generalized to other subjects, such as, to name but a few, geography, history, or languages. Such generalization presupposes careful theoretical preparations.

In conclusion, the findings of this study indicated that the application of the LC approach is effective in lower secondary education physics/chemistry classes. The results revealed that the effectiveness of this approach encompasses the cognitive, emotional, and behavioral dimensions of students' learning. It was also demonstrated that students who attend low-track schools in Austria are likely to benefit from this specific type of moderate constructivist teaching, suggesting that this approach, although it is rather demanding, does not discriminate between learners with (on average) low(er) achievement (and motivation) levels. There is, however, reason to believe that students' adaptation to the LC approach needs sufficient time; this informed the decision to conduct a long-term intervention study.

With regard to practical implications, the following aspects must be considered: If the LC approach is applied to regular school science instruction, teachers need to be appropriately trained in this method (to avoid the implementation of low-quality LC teaching, e.g., Lindgren and Bleicher 2005), the application must be monitored (e.g., through classroom observations and continuous reflection), and teachers must be made aware that they should not expect instant effects, particularly with regard to cognitive development and the change in students' trait emotions.

Acknowledgements We thank the "Industriellenvereinigung" (Industrial Association Salzburg) for the received funding for the research project.

Funding Information Open access funding provided by Paris Lodron University of Salzburg. 


\section{Appendix}

Learning Cycle "Is water an element or a chemical compound?"

Initial lessons in chemistry deal, among other things, with the central question of how the matter that makes up our world is constructed and how it can be systematized. First of all, the scientific concept of matter must be introduced or justified. In contrast to the everyday meaning of the term "substance", in the natural sciences all materials are referred to as substances. The term "substance", thus, forms the umbrella term for the differentiation into pure substances and mixtures. Pure substances can then be elements or compounds, mixtures are divided into homogeneous and heterogeneous mixtures.

Water as the most important substance on our planet is certainly a suitable prototype for developing the structure of matter. The learning cycle "Is water an element or a compound?" presented below goes back to a proposal by Lawson (2002). It is in its central question based on the Four Elements model from antiquity: At that time, it was assumed that all matter was composed of the four basic elements water, fire, air and earth. So, if water were an element or basic material, it could not be further broken down into other, elementary materials because it would already be an elementary basic component of the material world itself

In the following, we will show how the three phases Romance, Precision and Generalization are structured in this learning cycle. Subsequently, a possible transition into a subsequent learning cycle "There are dissolved substances in water" is outlined in brief form.

Romance phase:

The question of whether water can be broken down into further components or not is to be clarified with the help of a small student experiment: The teacher provides the group of pupils with a simple electrolysis apparatus made of disposable syringes and steel needles. Water is filled into a plastic tub and the experimental apparatus is set up (Fig. 1). The poles of the apparatus are connected to the poles of a DC voltage source. The students can observe that, when the electric circuit is closed, gas is generated in both syringe bodies. Based on this observation, the following question will be discussed:

- What could it mean that gases are formed in the two water-filled syringes as soon as the current flows?

- What is the ratio of the quantities of gas in the two syringes?

- What (preliminary) explanations/hypotheses do the students have for this phenomenon?

Precision phase:

After finishing the experimental phase and formulating their hypotheses on the observations made, the teacher initiates a whole-class teaching phase to discuss the results. All experimental groups report their observations and explanatory approaches in brief statements. What should remain unanswered is the question about the nature of the two quantities of gas produced in the syringes. In the demonstration experiment, the teacher shows that the larger of the two quantities of gas can be ignited with a lighted splint and that it burns with a 'squeaky pop' sound. The other gas body, on the other hand, is not combustible but re-ignites the flame of a glowing splint. This gas, therefore, supports combustion. The discussion will continue: Two gaseous substances with different properties are formed from liquid water. Based on these findings, the hypotheses of the individual groups are tested. Water can, thus, be split into two different gases with the help of electric power. It is, consequently, not an element but a chemical compound! The teacher explains to the pupils that the two gases are hydrogen and oxygen. Since they are available in a ratio of 1:2 in all experimental groups, statements about the quantitative composition of water molecules can be derived: The water molecule contains twice as many bound hydrogen atoms as oxygen atoms. The general law of formation of water from hydrogen and oxygen is formulated in the form of the reaction equation.

Generalization phase:

In another small student experiment, the experimental groups are each given a sample with tap water and one with distilled water. In both cases, it is "clean" water. Both samples could therefore be pure substances. The groups are asked to heat approx. 5 nil of each of the two water samples in two clean sample tubes in the burner flame until all the water has evaporated and the sample tubes are dry again. In one test tube a delicate white coating (solid) remains, in the other no residue can be observed.

In another small experiment, the groups are asked to add some powdered curd soap to both water samples and to shake them in closed vessels. In one vessel, a rich foam is formed after a short agitation; the soap solution remains clear. In the other vessel, almost no foam is formed; the soap solution remains cloudy.

The pupils are asked to discuss their observations and to provide first explanations (hypotheses).

The results are again discussed and presented. It seems that water contains sometimes more, sometimes less or sometimes no substances at all. Only distilled water seems to be a pure substance. Tap water contains at least one dissolved substance, which forms a white film during evaporation, and hinders foam formation when soap is added. How could one track down this substance "hidden" in water...?

Transition to the following learning cycle: "There are dissolved substances in water" (keyword) 
Romance phase:

The experimental groups each receive a drinking water sample from a collection of samples from different drinking water sources (ideally from the city of Salzburg).

The fact that the samples differ is not communicated to the groups. They only learn that it is drinking water from the region. Using a simple procedure (titration using a test substance), the groups obtain a test value for each of their water samples. The test values of the groups are compared. They differ from each other.

Based on this observation, the following question will be discussed:

- What (preliminary) explanations/hypotheses do the students have for the different test values?

Precision phase:

The test values of the groups are discussed with the whole class and are clearly presented in a table. The groups' hypotheses about this result are collected and discussed regarding plausibility.

The teacher informs the students that the test value represents the content of dissolved calcium ions (water hardness). He/she reveals that these are different drinking water samples (from the urban area of Salzburg) and names the places where the samples were taken from.

The discussion will continue. The assumption that drinking water even from a limited spatial area may differ in terms of water hardness as soon as it comes from different sources can be confirmed based on researched data from the regional drinking water supplier (e.g. Salzburg AG's water hardness plan for the urban area of Salzburg).

Generalization phase:

Different solids (possibly also liquids) are tested for their solubility in water. The following categorization can be established: Some substances dissolve well, some poorly, some not at all.

Literature:

Lawson (2002): Science Teaching and the Development of Thinking. Belmont CA: Wadsworth. p. 454

Open Access This article is licensed under a Creative Commons Attribution 4.0 International License, which permits use, sharing, adaptation, distribution and reproduction in any medium or format, as long as you give appropriate credit to the original author(s) and the source, provide a link to the Creative Commons licence, and indicate if changes were made. The images or other third party material in this article are included in the article's Creative Commons licence, unless indicated otherwise in a credit line to the material. If material is not included in the article's Creative Commons licence and your intended use is not permitted by statutory regulation or exceeds the permitted use, you will need to obtain permission directly from the copyright holder. To view a copy of this licence, visit http://creativecommons.org/licenses/by/4.0/.

\section{References}

Abraham, M. R., \& Renner, J. W. (1986). The sequence of learning cycle activities in high school chemistry. Journal of Research in Science Teaching, 23(2), 121-143.

Adey, P., Shayer, M., \& Yates, C. (2001). Thinking science: the curriculum materials of the CASE project (3rd ed.). London: Nelson Thornes.

Alfieri, L., Brooks, P. J., Aldrich, N. J., \& Tenenbaum, H. R. (2011). Does discovery-based instruction enhance learning? Journal of Educational Psychology, 103(1), 1-18.

Balci, S., Cakiroglu, J., \& Tekkaya, C. (2006). Engagement, exploration, explanation, extension, and evaluation (5E) learning cycle and conceptual change text as learning tools. Biochemistry and Molecular Biology Education, 34(3), 199-203.

Bunge, M. (2017). Philosophy of science (Vol. I: From problem to theory; Vol. II: From explanation to justification). London: Routledge.

Campbell, T. C., \& Fuller, R. (1982). Piagetian programs in higher education. Lincoln: University of Nebraska Press Retrieved from https://digitalcommons.unl.edu/cgi/viewcontent.cgi?article=1010\&context=adaptessays.

Cohen, J. (1988). Statistical power analysis for the behavioral sciences. Hillsdale: Erlbaum.

Dewey, J. (1916). Method in science teaching. General Science Quarterly, 1, 3-9.

Ellsworth, P. C. (2013). Appraisal theory: old and new questions. Emotion Review, 5(2), 119-124.

Franke, G., \& Bogner, F. X. (2013). How does integrating alternative conceptions into lessons influence pupils' situational emotions and learning achievement? Journal of Biological Education, 47(1), 1-11. 
Frenzel, A. C., Goetz, T., \& Pekrun, R. (2009). Emotionen (Emotions). In E. Wild et al. (Eds.), Pädagogische Psychologie (pp. 205-232). Heidelberg: Springer.

Frey, A., Taskinen, P., Schütte, K., Prenzel, M., Artelt, C., Baumert, J., Blum, W., Hammann, M., Klieme, E., \& Pekrun, R. (2009). PISA 2006. Skalenhandbuch. Dokumentation der Erhebungsinstrumente (PISA 2006. Scale handbook). Münster, Germany: Waxmann.

Fröhlich, G., Sellmann, D., \& Bogner, F. X. (2013). The influence of situational emotions on the intention for sustainable consumer behaviour in a student-centred intervention. Environmental Education Research, 19(6), 747-764.

Gläser-Zikuda, M. (2010). Emotionen (Emotions). In T. Hascher \& B. Schmitz (Eds.), Pädagogische Interventionsforschung (pp. 111-132). Weinheim \& München: Juventa.

Gläser-Zikuda, M., Fuß, S., Laukenmann, M., Metz, K., \& Randler, C. (2005). Promoting students' emotions and achievement-instructional design and evaluation of the ECOLE-approach. Learning and Instruction, 15(5), 481-495.

Goetz, T., Frenzel, A. C., Pekrun, R., \& Hall, N. C. (2006). The domain specificity of academic emotional experiences. The Journal of Experimental Education, 75(1), 5-29.

Goetz, T., Cronjäger, H., Frenzel, A. C., Lüdtke, O., \& Hall, N. C. (2010). Academic self-concept and emotion relations: domain specificity and age effects. Contemporary Educational Psychology, 35, 44-58.

Hong, J. C., Hwang, M.-Y., Tai, K.-H., \& Tsai, C. R. (2017). An exploration of students' science learning interest related to their cognitive anxiety, cognitive load, self-confidence and learning progress using inquiry-based learning with an iPad. Research in Science Education, 47, 1193-1212.

Jansen, M., Scherer, R., \& Schroeders, U. (2015). Students' self-concept and self-efficacy in the sciences: differential relations to antecedents and educational outcomes. Contemporary Educational Psychology, 41, $13-24$.

Karplus, R. (1979). Teaching for the development of reasoning. In A. Lawson (Ed.), 1980 AETS Yearbook: the psychology of teaching for thinking and creativity. ERIC/SMEAC: Columbus.

Karplus, R., \& Thier, H. D. (1967). A new look at elementary school science. Chicago: Rand McNally.

Kirschner, P. A., Sweller, J., \& Clark, R. E. (2006). Why minimal guidance during instruction does not work: an analysis of the failure of constructivist, discovery, problem-based, experiential, and inquiry-based teaching. Educational Psychologist, 41, 75-86.

Lawson, A. E. (2002). Science teaching and the development of thinking. Belmont: Wadsworth/Thomson Learning.

Lawson, A., Abraham, M., \& Renner, J. (1989). A theory of instruction. Using the learning cycle to teach science concepts and thinking skills. Manhattan: National Association for Research in Science Teaching.

Lindgren, J., \& Bleicher, R. E. (2005). Learning the learning cycle: the differential effect on elementary preservice teachers. School Science and Mathematics, 105(2), 61-72.

Liu, C.-J., Hou, I.-L., Chiu, H.-L., \& Treagust, D. F. (2014). An exploration of secondary students' mental states when learning about acids and bases. Research in Science Education, 44, 133-154.

Lombard, M. (2010). Intercoder Reliability. Retrieved from http://matthewlombard.com/reliability/

Marek, E. A., \& Methven, S. B. (1991). Effects of the learning cycle upon student and classroom teacher performance. Journal of Research in Science Teaching, 28(1), 41-53.

Möller, K. (2016). Bedingungen und Effekte qualitätsvollen Unterrichts - ein Beitrag aus fachdidaktischer Perspektive (Antecedents and effects of quality instruction). In N. McElvany, W. Bos, G. H. Holtappels, M. M. Gebauer, \& F. Schwabe (Eds.), Bedingungen und Effekte guten Unterrichts (pp. 43-64). Waxmann: Münster.

Muis, K. R., Chevrier, M., \& Singh, C. A. (2018). The role of epistemic emotions in personal epistemology and self-regulated learning. Educational Psychologist, 53, 165-184.

Musheno, B. V., \& Lawson, A. E. (1999). Effects of learning cycle and traditional text on comprehension of science concepts by students at different reasoning levels. Journal of Research in Science Teaching, 36(1), 23-37.

Oliver, M., \& Venville, G. (2016). Bringing CASE in from the cold: the teaching and learning of thinking. Research in Science Education, 47, 49-66.

Pekrun, R. (2006). The control-value theory of achievement emotions: assumptions, corollaries, and implications for educational research and practice. Educational Psychology Review, 18, 315-341.

Pekrun, R., Goetz, T., \& Frenzel, A. C. (2005). Achievement Emotions Questionnaire-Mathematics (AEQ-M). German version. User's manual. Munich: LMU.

Pekrun, R., Cusack, A., Murayama, K., Elliot, A. J., \& Thomas, K. (2014). The power of anticipated feedback: effects on students' achievement goals and achievement emotions. Learning and Instruction, 29, 115-124.

Piaget, J. (1952). The origins of intelligence in children. New York: International University Press.

Piaget, J. (1985). Equlilibration of cognitive structures: the central problem of intellectual development. Chicago: University of Chicago Press. 
Randler, C., Hummerl, E., Gläser-Zikuda, M., Vollmer, C., Bogner, F. X., \& Mayring, P. (2011). Reliability and validation of a short scale to measure situational emotions in science education. International Journal of Environmental \& Science Education, 6(4), 359-370.

Randler, C., Wüst-Ackermann, P., Im Kampe, V. O., Meyer-Ahrens, I. H., Tempel, B. J., \& Vollmer, C. (2015). Effects of expressive writing effects on disgust and anxiety in a subsequent dissection. Research in Science Education, 45, 647-661.

Renner, J. W. (1982). The power of purpose. Science Education, 66(5), 709-716.

Renner, J. W., Abraham, M. R., \& Birnie, H. H. (1988). The necessity of each phase of the learning cycle in teaching high school physics. Journal of Research in Science Teaching, 25(1), 39-58.

Riffert, F. (2008). Lernzyklen und ihre Beobachtung im Unterricht-Zwischenbericht zur Entwicklung eines Beobachtungsinstruments (Learning cycles and their observation). Salzburger Beiträge zur Erziehungswissenschaft, 12, 67-99.

Riffert, F., Hascher, T., Kriegseisen, J., \& Hagenauer, G. (2009). Testing Whitehead's theory of learning and instruction. A report from a pilot study. Tattva, 1(2), 45-56.

Schunk, D. H., \& DiBenedetto, M. K. (2016). Self-efficacy theory in education. In K. R. Wentzel \& D. B. Miele (Eds.), Handbook of motivation at school (pp. 34-54). New York: Routledge.

Shayer, M., \& Adhami, M. (2007). Fostering cognitive development through the context of mathematics: results of CAME project. Educational Studies in Mathematics, 64, 265-291.

Shayer, M., Adey, P., \& Wylam, H. (1981). Group test of cognitive development. Ideals and realization. Journal of Research in Science Teaching, 18, 157-168.

Sinatra, G. M., Broughton, S. H., \& Lombardi, D. (2014). Emotions in science education. In R. Pekrun \& L. Linnenbrink-Garcia (Eds.), International handbook of emotions in education (pp. 415-436). New York: Routledge.

Skinner, E., Furrer, C., Marchand, G., \& Kindermann, T. (2008). Engagement and disaffection in the classroom: part of a larger motivational dynamic? Journal of Educational Psychology, 100(4), 765-781.

Staver, J. R., \& Shroyer, M. G. (1994). Teaching elementary teachers how to use the learning cycle for guided inquiry instruction in science. In L. Schafer (Ed.), Behind the methods class door: educating elementary and middle school science teachers (pp. 1-11). Columbus: ERIC Clearinghouse Retrieved from https://genesismission.jpl.nasa.gov/educate/kitchen/foodthought/staver.html.

Tomas, L., \& Ritchie, S. M. (2012). Positive emotional responses to hybridized writing about a socio-scientific issue. Research in Science Education, 42, 25-49.

Van Griethuijsen, R. A. L. F., van Eijck, M. W., Haste, H., et al. (2015). Global patterns of students' views of science and interest in science. Research in Science Education, 45(4), 581-603.

Venville, G., \& Oliver, M. (2015). The impact of cognitive acceleration programme in science on students in an academically selective high school. Thinking Skills and Creativity, 15, 48-60.

Whitehead, A. N. (1917). The organization of thought. London: William \& Norgate.

Whitehead, A. N. (1929/1967). The aims of education and other essays. New York: Free Press.

Publisher's Note Springer Nature remains neutral with regard to jurisdictional claims in published maps and institutional affiliations.

\section{Affiliations}

\section{Franz Riffert $^{1} \cdot$ Gerda Hagenauer $^{2}$ - Josef Kriegseisen ${ }^{3} \cdot$ Alexander Strahl $^{4}$}

1 Department of Educational Science, University of Salzburg, Salzburg, Austria

2 Department of Educational Science, School-based Research and Practice in the School of Education, University of Salzburg, Salzburg, Austria

3 Institute of Didactics, Teaching and School Development, University of Teacher Education, Salzburg, Austria

4 Department of Science Instruction in the School of Education, University of Salzburg, Salzburg, Austria 